IZADP No. 2857

The Effect of Incentive Structure on Heuristic Decision Making: The Proportion Heuristic

Robert J . Oxoby

J une 2007 


\title{
The Effect of Incentive Structure on Heuristic Decision Making: The Proportion Heuristic
}

\author{
Robert J. Oxoby \\ University of Calgary \\ and IZA
}

\author{
Discussion Paper No. 2857 \\ June 2007
}

IZA
P.O. Box 7240
53072 Bonn
Germany

Phone: +49-228-3894-0

Fax: +49-228-3894-180

E-mail: iza@iza.org

\begin{abstract}
Any opinions expressed here are those of the author(s) and not those of the institute. Research disseminated by IZA may include views on policy, but the institute itself takes no institutional policy positions.

The Institute for the Study of Labor (IZA) in Bonn is a local and virtual international research center and a place of communication between science, politics and business. IZA is an independent nonprofit company supported by Deutsche Post World Net. The center is associated with the University of Bonn and offers a stimulating research environment through its research networks, research support, and visitors and doctoral programs. IZA engages in (i) original and internationally competitive research in all fields of labor economics, (ii) development of policy concepts, and (iii) dissemination of research results and concepts to the interested public.
\end{abstract}

IZA Discussion Papers often represent preliminary work and are circulated to encourage discussion. Citation of such a paper should account for its provisional character. A revised version may be available directly from the author. 


\begin{abstract}

\section{The Effect of Incentive Structure on Heuristic Decision Making: The Proportion Heuristic}

When making judgments, individuals often utilize heuristics to interpret information. We report on a series of experiments designed to test the ways in which incentive mechanisms influence the use of a particular heuristic in decision-making. Specifically, we demonstrate how information regarding the number of available practice problems influences the behaviors of individuals preparing for an exam (the proportion heuristic). More importantly the extent to which this information influences behavior depends critically on the way in which performance incentives are structured. In particular, relative compensation schemes magnify the influence of this heuristic while joint compensation schemes dampen its influence. We discuss these results with respect to the literature on effective compensation.
\end{abstract}

JEL Classification: C9, M5

Keywords: performance judgments, heuristics, incentives, experiments

Corresponding author:

Robert J. Oxoby

Department of Economics

University of Calgary

2500 University Drive NW

Calgary, Alberta T2N 1N4

Canada

E-mail: oxoby@ucalgary.ca

* Financial support from the Social Sciences and Humanities Research Council of Canada is gratefully acknowledged. 


\section{Introduction}

When forming subjective beliefs or making judgments, decision theory prescribes individuals use all available relevant information. However, in accord with theories of bounded rationality, this may prove to be an unwieldy and costly task. As a result, individuals often fall back on the use of cues and heuristics to facilitate information processing and belief formation. Given that these heuristics save cognitive resources, their use appears to be accentuated under cognitively multi-faceted circumstances or when judgments reflect on one's self-esteem, as in when individuals form judgments or beliefs about themselves or must evaluate and judge the quality of their efforts (e.g. having done a "good job;” Aronson, 1994; Langer, 1975).

For example, an individual working on the shop floor may evaluate the speed at which she works (e.g. productivity, work effort) based on her assessment of her own ability and the incentives she is provided by the employer. Similarly, a student will prepare for an exam based on her existing knowledge of the subject matter and the incentive to receive a good grade. It is clear that in each of these decisions, incentives (wages and grades) and perceived ex ante readiness (skills and knowledge) play an important role in motivating behavior.

To the extent that judgments regarding ability and performance reflect on one's selfimage, these judgments may carry greater subjective import, thereby increasing the information processing necessary to arrive at a judgment and making the use of heuristics more likely. To the extent that the use of heuristics result in information processing which differs from more traditional decision theoretic models, the aforementioned worker's and student's judgments about own performance or exam readiness will also differ from the predictions of traditional theoretic models. 
In this paper, our interest is in analyzing the relationship between an individual's use of a particular heuristic and the incentives she faces. That is, does the structure of incentives affect the way individuals use heuristics when making judgments about their preparatory behaviors (i.e. use and interpret information)? Our conjecture is that the structure of incentives not only directly motivates behavior (e.g. work effort) but also plays an important indirect role in motivating how individuals use information to form judgments about their efforts and abilities.

Through a series of experiments, we attempt to shed light on the way in which the structure of incentives (i.e. how compensation for a task is determined rather than how much compensation is provided) influences the use of an irrelevant cue. Specifically, under different incentive structures, we analyze how individuals use irrelevant information regarding number of available practice problems to prepare for an exam. As demonstrated by Josephs, Giesler, and Silvera (1994) and Silvera, Josephs amd Giesler (2001), individuals may use superficial cues to calibrate ex ante judgments about abilities and preparedness for a task. In our context, one such cue may be the share of available practice problems completed (the "proportion heuristic;” Silvera et al., 2001). That is, rather than use the number of actual practice problems solved to measure exam readiness, individuals use the fraction of problems completed to gauge preparedness. Silvera et al. (2001) found that problem set size served as a heuristic not only in determining individuals’ preparatory behaviors, but also their judgments about readiness: individuals who received larger problem sets completed more practice problems but a smaller proportion of available problems. These individuals reported lower judgments of own readiness than did individuals receiving smaller problem sets. This was true even when participants knew problem set size was arbitrarily determined. This effect was dubbed the "proportion heuristic" in recognition that individuals were basing preparatory 
behavior and readiness on the proportion of practice problems completed.

We posit that the structure of incentives influences the validity individuals attach to available and easily measurable information in a decision context. Thus, the degree to which problem set size serves as a cue in determining preparatory efforts may be susceptible to the manner in which rewards are given. Our current objective is to determine how the reliance on problem set size as a cue is influenced by the way incentives are presented. That is, just as framing outcomes as gains and losses influences decision-making (Tversky and Kahneman, 1981; Kahneman, Knetch and Thaler, 1991), the structure of incentives may also serve as a frame of reference for the use of information when making judgments. As such, our experiments complement research demonstrating how incentives influence the ways in which individuals construe the intentions of others (e.g., Gneezy, 2004) and the entitlements of others (e.g., Cherry, Frykblom and Shogren, 2002).

Research in psychology has noted that individuals often use judgment strategies based on readily available and computationally simple information. In two seminal papers Tversky and Kahneman (1973) and Kahneman and Tversky (1973) argue that individuals’ judgments often incorporate information that is available and representative of similar decision environments. Further, individuals may not utilize all available information, opting instead to use an information partition minimizing the burden on cognitive processes (Pelham, Sumarta and Myaskovsky, 1994; Sen, 1986; Simon, 1982) or rationally ignoring information (Berg, 2005; Goldstein and Gigerenzer, forthcoming). More germane to our experiment, there is substantial evidence that individuals find it easier to utilize quantitative cues when making decisions and forming judgments (e.g. Josephs et al., 1994).

From the standpoint of our experiment, we are agnostic as to the effect of heuristics (and in particular the proportion heuristic) from a normative perspective. While some 
researchers have argued that the presence of heuristic based decision making may result in biases resulting in suboptimal outcomes (e.g. Kahneman, Slovic and Tversky, 1982; Rabin and Schrag, 1999, Mullainathan, 2002) others have argued that the use of heuristics may confer advantages to decision makers (Berg, 2003; Gigerenzer and Todd, 1999). For example, Barber and Odean (2001) and Odean (1998) find that reliance on heuristics impose direct pecuniary costs on private investors in financial markets. On the other hand, Berg (2005) and Goldstein and Gigerenzer (forthcoming) find that individuals may outperform other decisions makers by choosing to limit the information utilized in decision making (i.e. choosing to rationally ignore relevant information). In the end, the normative effect of using a heuristic will largely depend on the decision environment in which the heuristic is employed. As such, there exist environments in which reliance on the proportion heuristic will enhance or diminish performance, yielding optimal or suboptimal outcomes. Our focus is not on directly testing the normative aspects of the proportion heuristic but rather to explore how different compensation mechanisms affect the manner in this heuristic is manifest. Our experiment is designed without a direct cost of relying on this heuristic and therefore cannot speak to the direct normative aspects of the proportion heuristic.

The remainder of the paper is organized as follows: section 2 describes the experiments and presents our results. We show that regardless of the structure of incentives, irrelevant information regarding problem set size is used by participants when gauging the level of effort to exert in preparatory activities. Moreover, we find that the structure of incentives has an important effect on the use of problem set size information: the effect of proportion heuristic is magnified when compensation is based on relative performance and dampened when incentives are based team performance. The final sections discuss and assess the implications our results. 


\section{The Experiment}

Our experiment focuses on individuals' judgments regarding preparing for a quiz. Specifically, we studied the effect of joint performance evaluations (i.e. team-based incentives) and relative performance evaluations (i.e. tournaments) preparatory activities conducted prior to an exam. Participants were seated at experimental stations separated from one another by dividers. The experimenter told participants that they would receive monetary, performance-based rewards from a ten minute exam consisting of twenty anagrams consisting of six and seven letter English words in which the letters had been scrambled.

Following Silvera et al. (2001), participants were given the opportunity to prepare for the test by solving anagrams from a list of either 50 (treatment variable: small problem set size) or 100 (treatment variable: large problem set size) practice problems. These problems sets were randomly assigned and participants were informed that other anagrams were available if they desired additional practice questions, there was no time limit for the practice questions, and that they should continue until they felt adequately prepared for the test.

The experimenter explicitly told participants that the size of the problem set had been determined arbitrarily by a coin toss at the start of the experimental session. One might naturally expect individuals to infer something about the nature of the exam based on the size of the problem set provided. For example, in a principal-agent setting, one may think of the agent forming inferences about the nature of an upcoming task based on the amount of preparatory work made available by the principal. Thus, an agent may infer the task at hand to be more difficult (and therefore require greater preparatory work) when offered a large number of training exercises. In such a setting, the amount of preparatory activities is an appropriate cue for evaluating readiness for a task. 
To minimize participants' inferences regarding task difficulty from the number of practice problems provided, participants in each session were informed that

Everyone in this session has received the same list of anagrams. This list was randomly chosen from two lists: one of 50 anagrams and one of 100 anagrams. If you would like a different list from the one you have received, you may request one from the experimenter. You should not take the size of the anagram list in front of you as any indication of the difficulty of the quiz you will be taking.

These steps were taken to minimize the potential that participants would perceive problem set size as an appropriate cue regarding the difficulty of the subsequent exam and, hence, the level of preparation required. ${ }^{1}$ As we note in our results, even if participants did infer task difficulty from problem set size, the effect problem set size appears to be markedly different across earnings treatments, suggesting that the structure of incentives influences the manner in which participants used problems that information.

Participants were told to put the problem set in a provided envelope once they had completed their preparations. In order to control for individuals completing problem sets at different times, participants were told they could use the computer at their stations once they had completed their preparations. ${ }^{2}$ Dividers and distance between stations made it difficult

\footnotetext{
${ }^{1}$ Focusing participants on the irrelevance of problem set size may have focused participants precisely on this aspect of the experiment. However, Silvera et al. (2001) found that individuals used problem set size in forming judgments even when they knew that problem set size was randomly determined. In their experiment 3 , individuals were randomly assigned problem sets and knew these assignments were random. Still, problem set size played a significant role in motivating behavior and in individuals' subjective evaluations of their own readiness. Given that our results are consistent with those of Silvera et al. (2001) we do not think the instructions significantly biased our results. Moreover, no participant requested the other problem set/ additional practice problems. This may have resulted from the priming (individuals thought the problem set they received was important in terms of size) or an "endowment effect" with respect to the assigned problem set.

${ }^{2} \mathrm{~A}$ monitor observed participants to ensure that the computers were used only after the participants had
} 
for individuals to determine if others were still working on the problem set or were using the computers. Our hope was that this would (i) limit the amount of unoccupied time individuals experienced if they completed their preparations earlier than others and (ii) limit any potential social pressure individuals who spent more time on the problem set may experience. Moreover, this allowed the experimenter to time how long each participant had spent on the practice problems: a small program used the activation of the computer to measure when individuals had stopped preparing for the exam.

To motivate effort, participants were assigned to one of three incentive conditions. In the no incentive (NI) condition individuals' behavior was not motivated by monetary incentives (replicating Silvera et al., 2001). That is, individuals received a fixed $\$ 10$ fee for participating in the experiment (i.e. preparing for and completing the anagram quiz). In the performance incentive treatments, individuals received a \$5 show-up fee and were randomly assigned into groups of six individuals. Within each group behavior was motivated by either joint performance evaluations (i.e. team-based incentives) or relative performance evaluations (i.e. tournaments). In the joint performance evaluation condition (JPE) individuals were told they would each receive $\$ 20$ if the sum of their group’s test scores was at least 100 . In the relative performance evaluation condition (RPE), a tournament reward of $\$ 20$ was given to the individual correctly solving the most anagrams in each group. ${ }^{3}$

Once all participants had completed their preparations, problem sets were collected and the timed exam began. Exams were scored with one point assigned to each correct answer. After the results were calculated, participants received payoffs in accord with the described incentive conditions. Across each treatment individuals were given the same lists of

completed their preparations.

${ }^{3}$ In the event of a tie, the reward was to be divided among those group members with the highest score. No ties occurred in the experiment. 
practice problems and the same anagram test. For all participants, numbers of practice problems solved and exam scores were private information. Payoffs were paid in private and earnings were private information.

\section{Results}

108 undergraduate students participated in the experiment, with 36 assigned to each incentive condition and, within that, half to each problem set size condition. Summary statistics for the NI, JPE, and RPE treatments are presented in Table 1.

(Insert Table 1 about here.)

To begin, we consider the effect of incentives on performance on the quiz. With respect to test scores, the evidence suggests that incentives matter. In both the small and large problem set treatments, participants in the JPE and RPE conditions did significantly better on the exam than participants in NI condition: Wilcoxon comparisons NI versus JPE and NI versus RPE yield $p<0.01$ regardless of problem set size. Thus, as expected, monetary incentives make a difference in motivating participants' exam performance, raising test scores by and average of 1.6 points. However, it is interesting to note that in the dimension of exam scores, we find no differences between JPE and RPE in either the large or small problem set treatment (Wilcoxon $p>0.40$ in all pair wise comparisons). That is, there appears to be no effect on test score due to the compensation mechanism (JPE versus RPE) and no effect due to problem set size (50 or 100).

In analyzing the experimental data with respect to preparatory behaviors, note that participants in the large problem set condition solved significantly more practice problems than did those in the small problem set condition regardless of earnings treatment. Following Silvera et al. (2001), this is evidence of the proportion heuristic: individuals on the proportion 
of problems they complete rather than the absolute number of preparatory questions answered. As such, individuals in the large problem set treatment answer significantly more questions than those in the small problem set condition. Kruskal-Wallis tests for equality of populations reject the hypothesis that preparatory behaviors between the conditions are drawn from the same distribution $\left(\chi^{2}=38.63, p<0.01\right)$. Thus, replicating Silvera et al. (2001), individuals used irrelevant problem set size information as a benchmark by which to gauge the (subjective) adequacy of preparatory behaviors. In terms of size effects, doubling the number of practice problems available resulted in an average increase of 1.50 (NI), 1.41 (JPE), and 1.58 (RPE) times increase in the number of practice problems completed.

More interesting, the difference in the number of practice problems solved was more pronounced under the RPE incentive than the JPE incentive. While there is no difference in the number of problems solved between the JPE and RPE incentive conditions in the small problem set treatment (Wilcoxon $p=0.80$ ), there is a significant difference in the large problem set treatment (Wilcoxon $p=0.02$ ). That is, individuals in the large problem set condition solved an average of $23 \%$ more practice problems when faced with the RPE incentive relative to the JPE incentive. Note that there was no difference between these two incentive conditions in the small problem set treatment. Thus, if one considers the effect of the problem set size on practice problems solved as measuring the use of the proportion heuristic, our results imply that under tournament based incentives individuals relied more heavily on heuristic decision making. That is, we observe greater divergence between numbers of problems solved (small versus large problem set size) under the RPE, suggestive of a larger effect of the proportion heuristic under RPE incentives relative to JPE incentives.

Thus, the structure of the incentives had an effect on the ways in which individuals 
judged their readiness for the quiz. Relative to the case with no incentives, the effect of problem set size on the number of practice problems solved (the proportion heuristic) was amplified by the use of tournament style incentives. Similarly, the effect of the proportion heuristic was diminished by the use of team based incentives. Strikingly, the differences in preparatory behaviors evidenced between the RPE and JPE treatments in the large problem set condition did not manifest themselves indifferences in test scores (Wilcoxon $p>0.60$ ). Thus, it does not appear that the increased practice exhibited in the large problem set conditions and between the JPE and RPE treatments resulted in better overall performance.

Under both the small and large problem set treatments, there was little difference in time spent preparing for the exam between the JPE and RPE conditions (Wilcoxon $p=0.73$ ), implying the need to consider the effect of incentive structure on problem solving rates. In this decision environment, where the quiz is timed, this rate may characterize individuals' preparatory efforts (or perceived urgency). In terms of average problem solving rates (i.e. seconds per practice problem), there is little difference between the NI and RPE conditions (Wilcoxon $p>0.30$ for each problem set size conditions) but problem solving rates differ between the JPE condition and the other conditions. With respect to the small problem set treatments, participants in the JPE condition had higher problem solving rates than in the NI and RPE conditions: Wilcoxon $p=0.03$ (NI) and $p=0.04$ (RPE). In the large problem set treatments, participants in the JPE condition took longer solving each problem relative to the other incentive conditions: Wilcoxon $p<0.01$ (NI) and $p=0.08$ (RPE).

\section{General Discussion}

As predicted by theories in economics and management, the presence of incentives increases 
preparatory behaviors and exam scores. Moreover, in line with previous research, we observe a strong proportion heuristic effect: individuals in the large problem set size condition engaged in greater preparatory behavior than did individuals receiving the small problem set. Surprisingly, this effect was consistent across earnings treatments and we find no evidence that greater preparation resulted in greater performance across the problem set size conditions.

More interestingly, the effect of problem set size was very different between the two incentive conditions. Under RPE, larger problem set size resulted in participants solving significantly more practice problems while participants under JPE did not significantly increase the number of problems solved when given a larger problem set. Thus, the effect of the proportion heuristic was magnified under RPE and dampened under JPE relative to the NI condition.

Within the management and organizational psychology literatures (e.g. Haslam, 2001; Mohrman, Cohen and Mohrman, 1995) tournament and team based compensation differs in ways going beyond their pure pecuniary motivational effects. Specifically, tournaments emphasize relative differences among individuals. This emphasis leads individuals to perceive additional beyond the pecuniary value of the tournament prize (e.g. social esteem; see Berger, Feisk, Norman and Wagner, 1998). This may emphasize the use of heuristics in decision making relative to the other environments where there are only pecuniary returns. On the other hand, under team based incentives indivdiuals' efforts have a public good aspect as one's preparatory efforts are appropriated not only by oneself but also by other members of the group (by presumably raising the likelihood of the group's aggregate score being at least 100). As such, while team based compensation can motivate feelings of trust an identity (Haslam, 2001; Kramer and Tyler, 1996), there is also a potential for free-riding. 
With an eye towards these differences, a potential explanation for our results lies in the intertwining of expectations states theories and theories of bounded rationality. First, drawing on theories of status characteristics and expectation states (Berger et al., 1998), the nature of the incentive mechanisms may engender different patterns of reasoning and belief formation. These differences are not only manifest through preparation, but performance. For example Lovaglia et al. (1998) conducted experiments in which individuals who were randomly labeled as low status performed significantly worse on tests of mental ability than those labeled high status. These results support the theory of status characteristics and expectation states in that the ersatz hierarchy developed in the experimental setting had real effects on the ex post hierarchy determined by tests scores. ${ }^{4}$

Secondly, theories of bounded rationality conjecture that decision makers have limited abilities or resources with which to make decisions. For example, Gabaix and Laibson (2000) develop a model of decision-making in which cognitive resources are scarce and state variables encode decision-makers' beliefs. Larger amounts of information can be thought of as increasing the number of state variables in any decision problem. To the extent that cognitive resources are scarce, the presence of additional information may tax these resources, resulting in poorer task performance. Alternately, one can consider the presence of information as increasing the deliberation costs one encounters during decision-making (as in Payne, Bettman and Johnson, 1993). By raising these costs, additional information may reduce the resources available during the performance of a task.

Here, one can interpret the tournament incentives as highlighting the relative differences among individuals in each treatment. That is, following the expectation states

\footnotetext{
${ }^{4}$ See Jemmott and Gonzalez (1989) and Markovsky et al. (1984) for similar experiments. Oxoby (2002) analyzes optimal compensation schemes when individuals beliefs accord with expectation states theories.
} 
theories of Berger et al. (1998), the status associated with winning the tournament emphasizes the ex ante status differences among participants. The emphasis on status information increases the number of state variables or the deliberation costs of decisions regarding preparatory activities. As a result, participants shift attention to the use of a simple cue (namely, problem set size) when choosing preparatory behaviors. On the other hand, participants faced with team-based incentives did not have the additional status information highlighted when forming judgments about exam readiness. This in turn reduces the individuals' reliance on problem set size as a cue in simplifying decision-making. Coupled with the incentive to free ride, this reduced the observed effect of the proportion heuristic on behaviors.

\section{Implications for Incentives and Organizations}

Our results yield insights into many areas of personnel economics and human resources management. The presence of the proportion heuristic implies that individuals may use an irrelevant cue in choosing the degree of effort to allocate to a task. As such, providing agents with greater opportunities for training may lead to an over-use of those resources, crowdingout efforts which should be allocated to other tasks and duties.

More interesting are the implications of these experiments for the design of incentives. One may think of the anagram tests as an ideal milieu for the use of tournament style rewards. Ex ante, the difficulty of the exam may be thought of as a common shock affecting all participants as exam difficulty was initially unknown and all participants took the same exam. Thus, the economic literature on incentives suggest the use of tournament 
style compensation schemes as the least costly means of motivating individual behavior. ${ }^{5}$ However, such a compensation scheme may magnify the use of problem set size in making preparatory decisions and judgments about own readiness for the exam. In a work place environment, this may naturally crowd out the employees' efforts required in other tasks, thereby compromising the quality of these efforts and their associated outcomes.

Team-based incentive mechanisms seem to have mitigated the effect of the proportion heuristic. Perhaps surprisingly, under team-based incentives, preparatory behaviors measured in terms of problem solving rates increased. Depending on the nature of the task at hand, greater efforts on this margin may translate into better overall preparation and hence performance. These aspects of incentive structure may explain the extensive use of teambased compensation schemes in practice. Mohrman et al. (1995) suggests that effective incentives in organizations should minimize competition (or at least the focus on competition) among employees, arguing rather for incentives that tie individuals' benefits together. In support of this claim, they find that many corporations use weaker team-based incentives over stronger tournament style incentives.

Our results point to another reason for the prevalence of team-based incentives and the relative dearth of tournament style incentives. Namely, tournaments may frame individual decision making in such a way that there is an over-use of simple cues and heuristics when forming expectations about abilities and probabilities of success. As a result, individuals may use simple heuristics (here the proportion heuristic) in making decisions. To the extent that these heuristics incorporate irrelevant information, their increased use may result in suboptimal decision-making and an inefficient allocation of agents' resources across various

\footnotetext{
${ }^{5}$ See Prendergast (1999) for a review of this literature and an analysis of the environments in which tournaments are inappropriate.
} 
activities in the work environment (e.g. overuse of training resources). Conversely, teambased incentives may frame information processing in a light that minimizes the use of these heuristics. This suggests that the reduced use of the proportion heuristic may make teambased incentives stronger mechanisms for motivating efficient allocations of efforts.

\section{References}

Aronson, E. (1994). The Social Animal. San Francisco: Freeman Press.

Barber, B. \& T. Odean (2001). Boys will be: Gender, overconfidence, and common stock investment. Quarterly Journal of Economics, 116(1), 261-292.

Berg, N. (2003). Normative behavioral economics. Journal of Socio-Economics, 3294), 411427.

Berg, N. (2005). Decision-making environments in which unboundedly rational decision makers choose to ignore relevant information. Global Business and Economics Review, 7(1), 59-73.

Berger, J., M.H. Fiesk, R.Z. Norman, \& D.G. Wagner (1998). Formation of reward expectations in status situations. In J. Berger \& M.H. Fiesk (Eds.), Status, Power, and Legitimacy. New Brunswick: Transaction Publishers.

Cherry, T.L., P. Frykblom, \& J.F. Shogren (2002). Hardnose the dictator. American Economic Review, 92(4), 1218-1221.

Conlisk, J. (1996). Why Bounded Rationality? Journal of Economic Literature, 34, 669-700.

Gabaix, X. \& D. Laibson (2000). Bounded rationality and directed cognition. MIT Department of Economics Working Paper.

Gigerenzer, G. \& P.M. Todd (1999). Fast and frugal heuristics: The adaptive toolbox. In G.

Gigerenzer, P. M. Todd, \& the ABC Research Group (Eds.), Simple Heuristics That Make Us Smart. New York: Oxford University Press.

Gneezy, U. (2004). The W effect of incentives. University of Chicago working paper.

Goldstein, D. G. \& G. Gigerenzer (forthcoming). The recognition heuristic and the less-ismore effect. In C. R. Plott \& V. L. Smith (Eds.), Handbook of Experimental Economics Results. North Holland: Elsevier. 
Haslam, A. (2001). Psychology in Organizations: The Social Identity Approach. London: Sage Publications.

Jemmott, J. \& E. Gonzalez (1989). Social status, the status distribution, and performance in small groups. Journal of Applied Social Psychology, 19, 584-598.

Josephs, R.A., R.B. Giesler, \& D.H. Silvera (1994). Judgment by quantity. Journal of Experimental Psychology: General, 123, 21-32.

Kahneman, D., J.L. Knetsch, \& R.H. Thaler (1991). The endowment effect, loss aversion, and status quo bias. Journal of Economic Perspectives, 5(1), 193-206.

Kahneman, D. \& A. Tversky (1973). On the psychology of prediction. Psychological Review, $80,237-251$.

Kahneman, D. \& A. Tversky (1979). Prospect theory: An analysis of decision under risk. Econometrica, 47(2), 263-91.

Kahneman, D., P. Slovic \& A. Tversky (1982). Judgment Under Uncertainty: Heuristics and Biases. Cambridge: Cambridge University Press.

Kramer, R. M. and T.R. Tyler (1996). Trust in Organizations. New York: Sage Publications.

Langer, E. J. (1975). The illusion of control. Journal of Personality and Social Psychology, 32(2), 311-328.

Lovaglia, M. J., J. W. Lucas, J. A. Houser, S. R. Thye, \& B. Markovsky (1998). Status processes and mental ability test scores. American Journal of Sociology, 104(1), 195228.

Markovsky, B., L. Smith, \& J. Berger (1984). Do status interventions persist? American Sociological Review, 49, 373-382.

Mohrman, S. A., S. G. Cohen, \& A. M. Mohrman (1995). Designing Team Based Organizations. San Francisco: Jossey-Bass.

Mullainathan, S. (2002). A memory based model of bounded rationality. Quarterly Journal of Economics, 117(3), 735-774.

Odean, T. (1998). Are investors reluctant to realize their losses? Journal of Finance, 53(5), 1775-1798.

Oxoby, R. J. (2002). Status characteristics, cognitive biases, and incentives in teams. Journal of Socio-Economics, 31(3), 301-316.

Payne, J. W., J.R. Bettman, \& E.J. Johnson (1993). The Adaptive Decision Maker. Cambridge: Cambridge University Press. 
Pelham, B.W., T. T. Sumarta, \& L. Myaskovsky (1994). The easy path from many too much: The numerosity heuristic. Cognitive Psychology, 26, 103-133.

Prendergast, C. (1999). The provision of incentives in firms. Journal of Economic Literature, 37 (1), 7-63.

Rabin, M. (1998). Psychology and economics. Journal of Economic Literature, 36(1), 11-46.

Rabin, M. \& J. Schrag (1999). First impressions matter: A model of confirmatory bias. Quarterly Journal of Economics, 114(1), 37-82.

Sen, A. (1986). Rationality and uncertainty. In L. Daboni, A. Montesano, and M. Lines (Eds.), Recent Developments in the Foundations of Utility and Risk Theory. Norwell, MA: Kluwer Academic.

Silvera, D. H., R. A. Josephs, \& R. B. Giesler (2001). The proportion heuristic: Problem set size as a basis for performance judgments. Journal of Behavioral Decision Making, 14(2), 207-221.

Simon, H. (1982). Models of Bounded Rationality. MIT Press.

Tversky, A. \& D. Kahneman (1973). Availability: A heuristic for judging frequency and probability. Cognitive Psychology, 5, 207-232.

Tversky, A. \& D. Kahneman (1981). The framing of decisions and the psychology of choice. Science, 211, 453-458. 


\begin{tabular}{|c|c|c|}
\hline & $\begin{array}{l}\text { small problem set } \\
\qquad(n=18 \text { each })\end{array}$ & $\begin{array}{l}\text { large problem set } \\
\qquad(n=18 \text { each })\end{array}$ \\
\hline $\begin{array}{l}\text { NI Condition } \\
\text { practice problems solved }\end{array}$ & $\begin{array}{c}14.67 \\
\sigma=6.66\end{array}$ & $\begin{array}{c}27.89 \\
\sigma=9.76\end{array}$ \\
\hline practice time (sec.) & $\begin{array}{c}427.00 \\
\sigma=177.33\end{array}$ & $\begin{array}{c}870.61 \\
\sigma=319.53\end{array}$ \\
\hline score on exam & $\begin{array}{c}14.00 \\
\sigma=2.25\end{array}$ & $\begin{array}{c}14.44 \\
\sigma=2.41\end{array}$ \\
\hline percent of sample & $16.67 \%$ & $16.67 \%$ \\
\hline $\begin{array}{l}\text { JPE Condition } \\
\text { practice problems solved }\end{array}$ & $\begin{array}{c}21.67 \\
\sigma=4.56\end{array}$ & $\begin{array}{c}29.28 \\
\sigma=8.01\end{array}$ \\
\hline practice time (sec.) & $\begin{array}{c}758.83 \\
\sigma=204.15\end{array}$ & $\begin{array}{c}1041.72 \\
\sigma=257.82\end{array}$ \\
\hline score on exam & $\begin{array}{c}16.72 \\
\sigma=1.49\end{array}$ & $\begin{array}{c}16.83 \\
\sigma=1.58\end{array}$ \\
\hline percent of sample & $16.67 \%$ & $16.67 \%$ \\
\hline $\begin{array}{l}\text { RPE Condition } \\
\text { practice problems solved }\end{array}$ & $\begin{array}{c}22.22 \\
\sigma=6.50\end{array}$ & $\begin{array}{c}36.17 \\
\sigma=7.46\end{array}$ \\
\hline practice time (sec.) & $\begin{array}{c}686.06 \\
\sigma=168.57\end{array}$ & $\begin{array}{c}1110.11 \\
\sigma=290.80\end{array}$ \\
\hline score on exam & $\begin{array}{c}16.61 \\
\sigma=2.09\end{array}$ & $\begin{array}{c}15.06 \\
\sigma=1.89\end{array}$ \\
\hline percent of sample & $16.67 \%$ & $16.67 \%$ \\
\hline
\end{tabular}

Table 1. Mean (and standard deviation) of preparation and performance under the incentive conditions. 